Psychology of Language and Communication 2014, Vol. 18, No. 2

GINA CONTI-RAMSDEN ${ }^{1}$, DOROTHY V. M. BISHOP ${ }^{2}$, BECKY CLARK ${ }^{3}$, COURTENAY FRAZIER NORBURY ${ }^{4}$, MARGARET J. SNOWLING ${ }^{2}$

${ }^{1}$ University of Manchester

${ }^{2}$ University of Oxford

${ }^{3}$ Independent Speech and Language Therapist, Surrey

${ }^{4}$ Royal Holloway, University of London

\title{
SPECIFIC LANGUAGE IMPAIRMENT (SLI): THE INTERNET RALLI CAMPAIGN TO RAISE AWARENESS OF SLI
}

\begin{abstract}
In this short article, we discuss what is specific language impairment (SLI) and why it is a hidden disability that few people have heard about. We describe the impact on research, policy and practice of SLI being a neglected condition. We end by providing the background and rationale of a new internet campaign, RALLI (www.youtube.com/rallicampaign), aimed at changing this state of affairs and raising awareness of SLI.

Key words: Specific Language Impairment (SLI), awareness, internet, youtube
\end{abstract}

Children learn and develop in interaction with others and language plays a key role in these interactions and the healthy development of young children (Kurcz, Shugar, \& Danks, 1986). One of the landmarks that parents look forward to is their baby's first words. Although a great deal of social-communicative development has occurred prior to this stage, the onset of use of the baby's home language signals an important advance in that child's development. Although it needs to be acknowledged that there is variation in the developmental timing of babies' first words, most parents will begin to worry about their child if she or he has not produced single words by 2 years of age.

Address for correspondence: Gina Conti-Ramsden, Communication and Deafness, School of Psychological Sciences, The University of Manchester, Ellen Wilkinson Building, Oxford Road, Manchester M13 9PL, UK. E-mail: gina.conti-ramsden@manchester.ac.uk 
There are many reasons why children may not produce their first words as expected. What is known is that delays or differences in patterns of language acquisition are sensitive indicators of developmental problems in preschool children. Difficulties with language can signal a number of problems, including hearing impairments, general learning disabilities and autism spectrum disorders. In addition, there are children who have difficulties with language, i.e. producing words to communicate and/or understanding what is said to them, whilst "everything else" appears to be normal. That "everything else" has traditionally been defined to include adequate input from the senses: normal hearing and normal/corrected vision. It also includes an adequate biological basis to develop language (they have no obvious signs of brain damage) and an adequate basis for learning, i.e., their nonverbal abilities as measured by IQ are similar to those of their peers of the same age. A desire to engage socially is also important: such children seek to interact socially with adults and peers and as such are not like children with autism who are not as socially engaged. These children are usually referred to as children with specific language impairment or SLI for short (Bishop \& Norbury, 2008). Because affected children look like their typically developing peers, SLI is a hidden disability.

Children with SLI find it effortful to learn to talk and these difficulties can be persistent. Given the importance of language to human behaviour, it is not surprising to find that language difficulties are a risk factor for associated difficulties in other aspects of children's lives. For example, research indicates developmental interactions between language impairments and difficulties acquiring literacy skills (Bishop \& Snowling, 2000) as well as more general nonverbal abilities throughout middle childhood, adolescence and beyond (Conti-Ramsden et al., 2012). There is evidence that children growing up with language impairment experience greater difficulties in social interaction than do typical children and adolescents (Durkin \& Conti-Ramsden, 2007). Still more broadly, children with language difficulties are at risk of less successful psychosocial and educational outcomes (Conti-Ramsden, Durkin, Simkin, \& Knox, 2009; Snowling et al., 2006; St Clair, Pickles, Durkin, \& Conti-Ramsden, 2011).

In contrast to dyslexia and autism, specific language impairment (SLI) is a neglected condition not only in research but also in debates about policy and practice (Bishop, 2009; Conti-Ramsden, 2009). A recent analysis of research publications and grants confirmed this impression, showing that SLI attracted far less research funding and led to fewer publications than many other conditions of comparable frequency and severity (Bishop, 2010). Perhaps the most striking comparison was with attention deficit hyperactivity disorder (ADHD), which is of similar prevalence to SLI and was rated by clinicians as comparable in severity of impact. Between 1985-2009, there were 1,140 publications on SLI in Web of Science, compared to 12,631 on ADHD. Between 2008 and 2009, funding was 19 times greater for $\mathrm{ADHD}$ than for SLI. It is fascinating to speculate on reasons 
for this neglect: one possibility is that the professional discipline associated with a disorder plays a role, so that conditions that are seen as the domain of medics receive more attention and better funding than those that are the focus of nonmedical disciplines such as speech and language therapy. Furthermore, SLI is a hidden disability and most individuals with SLI can talk, and their difficulties are not always obvious. Another factor may be the extent to which parent groups lobby for recognition and funds. This has been particularly striking in the case of autism, where parents have not only contributed substantial resources to autism research, but have also lobbied governments very effectively (Silverman \& Brosco, 2007). This simply hasn't happened to the same extent in the case of SLI. The fact that SLI is a familial condition means that some parents may themselves have language or literacy problems, and could find it daunting to challenge existing political, educational and financial structures.

Having identified the problem, the question was what to do about it (Bishop et al., 2012). At the end of 2011, we decided to take action, and formed a group with the name RALLI, standing for Raising Awareness of Language Learning Impairments. Our group consists of four academics, two of whom trained as speech and language therapists and two as clinical psychologists, together with a practising speech and language therapist. We decided that what was needed was a campaign to put accessible materials on the internet in a form that would attract attention from the general public. Our aim was not to raise money or to improve provision, but simply to improve the recognition of children's language impairments: we felt that this aim had to succeed before we could move on to more ambitious goals.

We benefitted enormously from financial support from the charities Afasic Cymru and the Waterloo Foundation, and from agreement of one of our funders, the Economic and Social Research Council to commit funds to our project as part of research dissemination. Other charities and research groups with allied interests have been enthusiastic about our vision and provided invaluable support via our advisory board. We received invaluable guidance from a Public Relations company, Teamspirit, who contributed pro bono advice and expertise to get the campaign up and running. It was quite an adventure for the group of us to undertake this challenge, which was unlike anything we had ever done before. We were all used to working hard with attention to detail, but had no experience of marketing our ideas - but this, as we gradually realised, was what we needed to do. In effect, we needed an advertising campaign to promote the idea of specific language impairment. This meant discarding some of our traditional notions about how to communicate. Scientific talks, bristling with powerpoints and sessions lasting 30 or more minutes were not going to be effective. We needed to facilitate the voice of young people and families affected by specific language impairment, have them take centre stage and tell their stories, so that people could relate to what they were hearing. We felt it was important, though, that 
we also provided information that was evidence-based, and that posed a challenge of how best to convey research results accurately and succinctly, without getting bogged down in detail.

In May 2012 we launched a YouTube channel (www.youtube.com/rallicampaign) in order to reach three target audiences: families of children who may have SLI, professionals working with children - particularly in education - and young people with SLI themselves. As well as learning more about how to go about promoting our ideas, we've all been thrust into the deep end and had to learn a great many new technical and creative skills, especially Becky Clark, our editor. Most of our budget goes on creating professional-quality short films, and we aim to release at least one of these every month, covering topics such as what it is like to be a parent of a child with SLI, what signs of language problems teachers can look out for, and how language problems may be missed if a child has reading difficulties. We know our budget won't go far, however, so we've also been making short videos ourselves using a handheld digital video camera. It's challenging to cover a topic such as 'What causes SLI?' in just three minutes, but we realise the important thing is to get across a simple message. We can then follow this message up by linking the video with a more in depth slide presentation and reference list, so that the evidence is there for those who want more detail.

One issue that we've had to confront is the terminological confusion that surrounds children's language impairments. There is growing evidence that, on the one hand, children who meet criteria for SLI can be very varied, and there are thorny questions about overlaps with autism and other developmental disorders. Another vexed question is the inclusion of nonverbal ability in the diagnostic criteria for SLI. In the past, it was usual to require a large discrepancy between verbal and nonverbal ability, but this doesn't seem to be very meaningful: it doesn't define an aetiologically distinct group (Bishop, 2004), doesn't necessarily map on to actual clinical populations (Stark and Tallal, 1981), and doesn't predict response to intervention (Bowyer-Crane, Duff, Hulme et al., 2011). We decided to focus first on those children whose nonverbal ability is in the normal range, but not necessarily substantially higher than verbal ability. We are also, initially at least, presenting a clear picture of SLI without explaining the likelihood of comorbidity with other developmental difficulties. Once we have established that these children do exist and need to have their voices heard, we will be ready to cover further diagnostic and terminological issues that inevitably arise in this field.

It has been amazing to see the results of harnessing the power of the internet, both on the speed of dissemination and on the breadth of audience - seen in the channel's global viewing statistics. One unexpected outcome has been the enthusiastic reception by an international audience, who have helped us create versions of our introductory "What is SLI?" video in a range of languages, including German, French, Spanish, Portuguese and Chinese. We have been encouraged by the interest from different language communities and we want to hear from 
anyone who may be interested in adding another language to our "What is SLI" playlist, so do get in touch with us.

There is, however still a long way to go and we urge you to look at our channel, subscribe, add your comments and forward the link to parents, fellow professionals, and friends. We are also keen to be responsive and hear what else you as viewers may want to see covered in the work of RALLI. You may even wish to create your own films that we can link to from our channel. As professionals working with young people with language impairment, we feel a responsibility to change the current neglect of this condition and we would welcome your involvement to help us make this campaign a success. Help us spread the word!

\section{References}

Bishop, D.V.M. (2004). Specific language impairment: diagnostic dilemmas. In L. Verhoeven \& H. Van Balkom (Eds.), Classification of Developmental Language Disorders (pp. 309-326). Mahwah, NJ.: Erlbaum.

Bishop, D.V.M. (2009). Specific language impairment as a language learning disability. Child Language Teaching and Therapy, 25 (2), 163-165.

Bishop, D.V.M. (2010). Which neurodevelopmental disorders get researched and why? PLoS One, 5 (11): e15112.

Bishop, D.V.M., Clark, B., Conti-Ramsden, G., Norbury, C.F., \& Snowling, M.J. (2012). RALLI: An internet campaign for raising awareness of language learning impairments. Child Language Teaching and Therapy, 28 (3), 259-262.

Bishop, D.V.M. \& Snowling, M.J. (2004). Developmental dyslexia and specific language impairment: same or different? Psychological Bulletin, 130 (6), 858-886. Bishop, D.V.M. \& Norbury, C.F. (2008). Speech and language impairments. In M. Rutter, D. Bishop, D. Pine, S. Scott, J. Stevenson, E. Taylor, \& A. Thapar (Eds.), Child and Adolescent Psychiatry, 5th Edition (pp. 782-801). Oxford: Blackwells.

Bowyer-Crane, C., Snowling, M.J., Duff, F., \& Hulme, C. (2011). The response to intervention of children with SLI and general delay. Learning Disabilities: A Contemporary fournal, 9(2), 107-121.

Conti-Ramsden, G. (2009) The field of language impairment is growing up. Child Language Teaching and Therapy 25: 166-168.

Conti-Ramsden, G., Durkin, K., Simkin, Z., \& Knox, E. (2009). Specific language impairment and school outcomes. I: Identifying and explaining variability at the end of compulsory education. International fournal of Language \& Communication Disorders, 44 (1), 15-35.

Conti-Ramsden, G., St. Clair, M.C., Pickles, A.P., \& Durkin, K. (2012). Developmental trajectories of verbal and nonverbal skills in individuals with a history of SLI: From childhood to adolescence. Fournal of Speech, Language, \& Hearing Research, 55 (6), 1716-1735. 
Durkin, K. \& Conti-Ramsden, G.M. (2007). Language, social behaviour, and the quality of friendships in adolescents with and without a history of specific language impairment. Child Development, 78 (5), 1441-1457.

Silverman, C. \& Brosco, J.P. (2007). Understanding autism: Parents and pediatricians in historical perspective. Archives of Pediatrics and Adolescent Medicine, 161 (4), 392-398.

Snowling, M.J., Bishop, D.V.M., Stothard, S.E., Chipchase, B., \& Kaplan, C. (2006). Psychosocial outcomes at 15 years of children with a preschool history of speech-language impairment. Journal of Child Psychology and Psychiatry, 47 (8), 759-765.

Stark, R.E. \& Tallal P. (1981). Selection of children with specific language deficits. fournal of Speech and Hearing Disorders, 46 (2), 114-122.

Kurcz, I., Shugar, G.W., \& Danks, J.H. (Eds.) (1986). Knowledge and language. Amsterdam: North-Holland.

St Clair, M.C., Pickles, A., Durkin, K., \& Conti-Ramsden, G. (2011). A longitudinal study of behavioural, emotional and social difficulties in individuals with a history of specific language impairment (SLI). Journal of Communication Disorders, 44 (2), 186-199. 